\title{
Glass ceiling em cargos de board e seu impacto no desempenho organizacional
}

\section{Glass ceiling in board charges and its impact on organizational performance}

Glass ceiling en cargos de board y su impacto en el desempeño organizacional

\section{Cristian Baú Dal Magro}

Doutorando em Ciências Contábeis e Administração - FURB

Mestre em Ciências Contábeis - FURB

Professor do curso de Ciências Contábeis pela Unochapecó

Endereço: Av. Coronel Ernesto Francisco Bertaso, 954, Sala 01, Centro,

CEP: 89.850-000 - Quilombo/SC, Brasil.

E-mail: cristianbaumagro@gmail.com

Telefone: (49) 3346-3060

\section{Andréia Carpes Dani}

Doutoranda em Ciências Contábeis e Administração - FURB

Mestre em Ciências Contábeis - FURB

Bolsista Capes

Rua Antônio da Veiga, 140 - Itoupava Seca,

CEP: 89012-900 - Blumenau/SC, Brasil

E-mail: andreiacarpesdani@gmail.com

Telefone: (47) 3321-0200

\section{Danielle Paná Vergini}

Mestre em Ciências Contábeis - FURB

Endereço: Rua Antônio da Veiga, 140 - Itoupava Seca,

CEP: 89012-900 - Blumenau/SC, Brasil

E-mail: danielle_vergini@hotmail.com

Telefone: (47) 3321-0200

\section{Marcia Zanievicz Silva}

Doutora em Ciências Contábeis e Administração - FURB

Professora do Programa de Pós-Graduação em Ciências Contábeis - FURB

Endereço: Rua Antônio da Veiga, 140 - Itoupava Seca,

CEP: 89012-900 - Blumenau/SC, Brasil

E-mail:marciaza@gmail.com

Telefone: (47) 3321-0200

Artigo recebido em 05/04/2016. Revisado por pares em 19/10/2017. Reformulado em 17/11/2017. Recomendado para publicação em 08/03/2018 por Carlos Eduardo Facin Lavarda (Editor-Chefe). Publicado em 28/03/2018. 


\title{
Resumo
}

A pesquisa buscou identificar a incidência de glass ceiling nos cargos de board e seu impacto no desempenho organizacional das companhias brasileiras de capital aberto. Para sua operacionalização, adotou-se uma abordagem quantitativa, analisando-se 61 empresas com alto volume de negociação ( $\mathrm{IBrX} 100$ ) na Bolsa de Valores do Brasil. Constatou-se que os investidores institucionais não criam barreiras à valorização das empresas que promovem igualdade de gênero nos cargos de board, ou seja, que possuem mulheres que atuam em cargos de diretoria, conselho de administração e presidência. Conclui-se que, quando o glass ceiling não incide nos cargos de diretoria e no conselho de administração, as empresas alcançam melhor desempenho financeiro e econômico, quando comparadas com aquelas que não possuem mulheres em tais cargos. A exemplo disso, verificou-se que a proporção de mulheres no conselho de administração influencia no retorno sobre o patrimônio líquido, e a proporção de mulheres na diretoria influencia no valor de mercado das organizações.

Palavras-Chave: Glass ceiling; Conselhos corporativos; Cargos de board; Desempenho organizacional

\begin{abstract}
The research sought to identify the incidence of glass ceiling in board positions and its impact on the organizational performance of Brazilian publicly traded companies. For its operation, a quantitative approach was adopted, analyzing 61 companies with high volume of trading (IBrX 100) on the Brazilian Stock Exchange. It was found that institutional investors do not create barriers to the valuation of the companies that promote gender equality in board positions, ie, that have women working in executive positions, advice and chair. We conclude that, when not imposed glass ceiling in management positions and the board of directors, the companies analyzed have better financial and economic performance, when compared to those that do not have women in such positions. As an example, it was found that the proportion of women on the board influences the return on equity, and the proportion of women in management influence on the market value.
\end{abstract}

Keywords: Glass ceiling; Corporate boards; Board positions; Organizational performance

\section{Resumen}

La investigación buscó identificar la incidencia de glass ceiling en los cargos de board y su impacto en el desempeño organizacional de las compañias brasileñas de capital abierto. Para su operacionalización, se adoptó un abordaje cuantitativo, analizando 61 empresas con alto volumen de negociación (IBrX 100) en la Bolsa de Valores de Brasil. Se constató que los inversores institucionales no crean barreras a la valorización de las empresas que promueven igualdad de género en los cargos de junta, es decir, que poseen mujeres que actúan en cargos de dirección, consejo de administración y presidencia. Se concluye que cuando el cristal de techo no se centra en los cargos de dirección y en el consejo de administración, las empresas alcanzan un mejor desempeño financiero y económico, cuando se comparan con aquellas que no poseen mujeres en tales cargos. A tal efecto, se verificó que la proporción de mujeres en el consejo de administración influye en el retorno sobre el patrimonio neto, y la proporción de mujeres en la dirección influye en el valor de mercado de las organizaciones.

Palabras clave: Glass ceiling; Consejos corporativos; Cargos de junta; Desempeño organizacional 


\section{Introdução}

Nos últimos anos, a diversidade de gênero é um tema que tem se destacado no meio acadêmico em função das implicações no contexto social e corporativo. Neste aspecto, pesquisadores tem buscado caracterizar o impacto financeiro e social causado pela manutenção na desigualdade de gênero em cargos de gestão nas organizações (PARENTE, 2013).

Esse contínuo interesse sobre a desigualdade de gênero nas organizações decorre, pelo menos em parte, pelo fato das mulheres serem discriminadas no ambiente de trabalho, mesmo tendo alcançado, nas últimas décadas, importantes conquistas sociais, profissionais, culturais e políticas. Giuberti e Menezes Filho (2005), Cambota e Pontes (2007) e a Organização das Nações Unidas para Igualdade de Gênero e o Empoderamento das Mulheres (UN-WOMEN, 2015), afirmam que a distinções entre homens e mulheres à ascensão na carreira e remuneração compatível ao cargo, são oriundas das barreiras invisíveis denominadas de glass ceiling.

No Brasil, a partir dos anos 1990, as empresas iniciaram políticas para a gestão da diversidade de gênero, as quais visaram não apenas o cumprimento da legislação, mas à geração de valor aos negócios (SANTOS et al., 2008). Embora a inserção das mulheres no mercado de trabalho registre progressos, além do acesso as profissões de prestígio e funções que, antes, eram ocupadas apenas por homens, ainda há um caminho complexo para a igualdade de gênero nos cargos de topo (BRUSCHINI, 2007; MADALOZZO, 2011; SOUZA; VOESE; ABBAS, 2015; TEIXEIRA; GÓIS, 2015; GONÇALVES et al., 2016; MARRY; POCHIC, 2017).

A literatura mais antiga já havia esboçado preocupação com as barreiras invisíveis que, na atualidade, ainda predominam sobre a progressão na carreira das mulheres nos cargos de alto escalão. Hultin e Szulkin (1999) argumentaram que a preparação acadêmica das mulheres para assumirem altos níveis de gestão, deveria ter tornado a desigualdade menos prevalecente. Contudo, a estrutura patriarcal mantida pelas organizações e defendida pela classe masculina, abreviou a habilidade das mulheres para alcançar o topo do escalão corporativo.

A literatura recente comprova a presença do glass ceiling nos dias atuais, sendo que Brasil, Pereira e Machado (2009) relatam que apesar das conquistas na inserção ao mercado de trabalho, muitos ainda questionam a atuação das mulheres nos níveis mais altos das organizações. Madalozzo (2011), Teixeira e Góis (2015), Gonçalves et al. (2016) e Marry e Pochic (2017) reforçam sobre a continuidade das barreiras invisíveis (glass ceiling) na ocupação dos cargos de alto nível organizacional pelas mulheres.

Ramdhony, Oogarah-Hanuman e Somir (2013) e Souza, Voese e Abbas (2015) adentraram, especificamente, na desigualdade de gênero no alto escalão da profissão contábil, sugerindo aumento no número de mulheres que ingressaram na carreira, mas essa mesma proporção não transpassa aos cargos de alto escalão da profissão. Portanto, a desigualdade no acesso às mais altas esferas deslocou-se das mulheres e de sua suposta falta de ambição, ligada à socialização familiar e às imposições de sua "vida dupla", para os privilégios concedidos aos homens em todas as etapas da vida, e em todas as esferas de atividade pelos efeitos da socialização de dominação masculina (MARRY; POCHIC, 2017).

$\mathrm{O}$ preconceito dirigido às mulheres no mercado de trabalho constitui-se, na maioria das vezes, em barreiras invisíveis que impedem o aumento nos rendimentos, progressão na carreira, ingresso em cargos superiores e valorização profissional. Tais barreiras são denominadas pelos pesquisadores como Glass Ceiling (MORRISON; GLINOW, 1990; BLAU; DEVARO, 2007; MADALOZZO, 2010). Mesmo as evidências indicando que a ocorrência do Glass Ceiling é uma prática organizacional comum na atualidade (BLAU; DEVARO, 2007; BJERK, 2008; MADALOZZO, 2010), pesquisadores têm sinalizado que participação feminina é importante para o mercado de trabalho, em especial na gestão e nos conselhos (DEWATRIPONT; JEWITT; TIROLE, 1999; WESTPHAL; MILTON, 2000; MARGEM, 2013). 
Neste tocante, estudos prévios demonstraram o impacto corporativo causado pela ocupação das mulheres no alto escalão das organizações. Santos et al. (2017) comprovaram que a presença feminina no conselho de administração reduz o endividamento. Huang e Kisgen (2013) e Faccio, Marchica e Mura (2016) relataram que as empresas administradas por CEO's mulheres fazem opções de financiamento e investimento menos arriscadas, do que as empresas similares dirigidas pelos CEO's do sexo masculino. Perryman, Fernando e Tripathy (2016) sugerem que a diversidade de gênero reduz os riscos e melhora o desempenho das empresas. A presença das mulheres no alto nível hierárquico tem sido fator crítico para elevação dos lucros (RAMDHONY; OOGARAH-HANUMAN; SOMIR, 2013).

Especificamente, no tocante à participação feminina no conselho de administração, a diversidade dos membros pode contribuir para capturar comportamentos e conhecimentos diversificados. Adicionalmente, Carter, Simkins e Simpson (2003) mencionam que o gênero na composição do conselho de administração, tem sido um importante instrumento de discussão pela governança corporativa. A incorporação da diversidade de gênero no conselho de administração e diretoria pode auxiliar na compreensão do mercado, aumento da criatividade e da inovação organizacional, fatores que podem auxiliar a atuação dos mecanismos de governança corporativa e refletem no desempenho (ROBINSON; DECHANT, 1997).

Observa-se crescente interesse no efeito da diversidade de gênero sobre o desempenho das organizações, embora, possivelmente devido à complexidade dessa relação, os estudos ainda não tenham obtido resultados conclusivos, havendo contradições (DOMÍNGUEZ; SÁNCHEZ; ÁLVAREZ, 2012) que indicam a necessidade de novas pesquisas. Nesse contexto, surge a questão-problema: qual a incidência de glass ceiling nos cargos de board e seu impacto no desempenho organizacional das companhias brasileiras de capital aberto? O objetivo do estudo foi identificar a incidência de glass ceiling nos cargos de board e seu impacto no desempenho organizacional das companhias brasileiras de capital aberto.

A participação das mulheres nos conselhos e em cargos de board tem sido discutida pela literatura internacional, por autores como Wolfers (2006), Lee e James (2007), Dobbin e Jung (2011), Huang e Kisgen (2013) e Faccio, Marchica e Mura (2016), bem como pela literatura nacional, por autores como Santos et al. (2017). Os resultados, embora ainda controversos, tendem a indicar que empresas com alta proporção de mulheres nos conselhos corporativos e em cargos de board apresentam melhor desempenho e maior valor de mercado (MARGEM, 2013; RAMDHONY; OOGARAH-HANUMAN; SOMIR, 2013; PERRYMAN; FERNANDO; TRIPATHY, 2016). Identifica-se uma lacuna de pesquisa, visto que a estrutura de governança corporativa, composição dos conselhos, atividades e comportamentos organizacionais e socioculturais são diferentes entre os países e, portanto, se faz necessário explorar com maior ênfase tais aspectos associados a desigualdade de gênero, no contexto brasileiro.

Em teoria, o estudo oferece argumentos comprobatórios do glass ceiling, no qual pode estar impedindo a inserção de mulheres no conselho de administração e na diretoria das companhias. Além disso, se discute a persistência do glass ceiling ao longo do tempo, em que o homem pode se utilizar de tal perspectiva teórica para promover a manutenção de seu estereótipo patriarcal no ambiente de trabalho.

No aspecto social, salienta-se que as companhias podem oportunizara ascensão das mulheres nos altos cargos da hierarquia e assim melhorar a qualidade de vida da sociedade e diminuir as desigualdades que ainda persistem. Com isso, a pesquisa visa promover novas tratativas e ações voltadas a redução da desigualdade de gênero. Na prática, minimizar a desigualdade de gênero nos altos cargos de gestão pode ser um contributo de que a não incidência de glass ceiling pode melhorar o desempenho econômico-financeiro organizacional e, portanto, os proprietários do capital, investidores, mercado e a própria sociedade patriarcal darão maior valor ao capital intelectual e a participação das mulheres nas decisões estratégicas. 


\section{Revisão da Literatura}

\subsection{Glass Ceiling nos Cargos de Board}

O Glass Ceiling foi introduzido na década de 1980, nos Estados Unidos, para descrever uma barreira invisível, criada pelos homens, que impossibilita a ascensão das mulheres nos níveis hierárquicos superiores, os quais, no contexto do estudo foram denominados de board (POWELL; BUTTERFIELD, 1994; OHLOTT; RUDERMAN; MCCAULEY, 1994). Morrison e Glinow (1990) foram precursores no uso da expressão Glass Ceiling ou "teto de vidro", ao verificarem que, na época, o governo dos Estados Unidos buscou regulamentar o mercado com o intuito de reduzindo as barreiras que, artificialmente, impediam as mulheres de: ingressar nas carreiras de board; e acessar promoções exclusivas dos homens. Na mesma direção, Wearing e Wearing (2004) investigaram o Glass Ceiling como uma barreira implícita que as mulheres enfrentam na ocupação dos altos cargos corporativos.

Nesse sentido, o Glass Ceiling ocorre porque a promoção interna é de responsabilidade dos gestores, e seus critérios não são públicos, representando uma barreira invisível para a oferta de progressão na carreira (MADALOZZO, 2010). Blau e Devaro (2007) corroboram mencionando que a progressão na carreira é menos provável às mulheres, do que aos homens, porque cria-se uma barreira, a partir dos preconceitos criados pelo mercado e na própria sociedade, em relação ao gênero. Bjerk (2008) relata que o Glass Ceiling não está relacionada apenas à desigualdade do gênero e/ou raça, mas também com a dificuldade de se estabelecer um padrão de avaliação das habilidades interpessoais necessárias para a ocupação de determinados cargos corporativos.

A ocorrência do Glass Ceiling tem sido, frequentemente, citada como a razão da baixa participação das mulheres no conselho de administração das companhias, pelo fato de restringir, de maneira informal, a ascensão em determinados campos de atuação e posições hierárquicas (GUTNER, 2001). Ademais, o preconceito contra as mulheres é agravado nas situações em que são rotuladas, em função do gênero, pela violação das expectativas de assunção aos riscos, metas financeiras e estabelecimento de estratégias agressivas (FISKE; TAYLOR, 1991; POWELL; BUTTERFIELD, 2002).

Daily, Certo e Dalton (1999) sugerem que o "teto de vidro" é uma barreira transparente que, ao permitir que as mulheres ocupem apenas determinadas funções de nível operacional, limita suas perspectivas de ascensão profissional. De acordo com Margem (2013), a diversidade de gênero nos conselhos das organizações ganhou relevância, nas discussões sobre as melhores práticas de governança corporativa, à medida que os países adotaram regras para a igualdade de oportunidades entre homens e mulheres nestes cargos.

O conselho de administração e conselho fiscal são órgãos que auxiliam no monitoramento das decisões de administradores, a fim de garantir o interesse dos proprietários do capital (ANDRADE et al., 2009). Escolhidos pelos acionistas, os conselheiros possuem poder para demitir e contratar executivos, bem como definir os cargos e níveis hierárquicos da alta administração. Volpin (2002) destaca que o conselho de administram tem o papel de fiscalizar e avaliar o desempenho dos executivos, buscando minimizar os conflitos de agência entre eles e os acionistas, tendo em vista a criação de valor para o proprietário do capital.

Para Silva e Magalhães Filho (2004), o poder de decisão encontra-se alocado nas mãos dos executivos, os quais são contratados pelos proprietários, através do conselho de administração, com a finalidade de representar os acionistas. Em consonância com Parente (2013), a atuação dos conselheiros de administração não está limitada as questões vinculadas aos objetivos financeiros, mas alcançam decisões estratégicas, táticas, operacionais e também aquelas vinculadas com a responsabilidade social corporativa. 
Finkelstein e Hambrick (1997) delinearam duas funções essenciais aos conselhos de administração, as quais estariam, fortemente, relacionadas com o desempenho financeiro das empresas. Em primeiro lugar, os conselheiros são atores influentes na determinação da direção estratégica e na tomada das decisões sobre o posicionamento atual da organização. Em segundo lugar, os conselheiros desempenham papel de monitoramento e supervisão, que pode incluir: representar os acionistas; controlar o uso adequado da riqueza; assumir riscos; contratar e compensar e monitorar o desempenho dos gestores de alto nível hierárquico.

O IBGC (2011) traçou um panorama do papel da mulher na estrutura dos conselhos de administração das empresas brasileiras de capital aberto (dados de 454 empresas, no ano de 2010, e 506 empresas, no ano de 2011). Entre os resultados, o IBGC (2011) contatou que as mulheres ocupavam, na época, $7,7 \%$ das posições nos conselhos de administração das companhias brasileiras listadas, que $66 \%$ dos conselhos não possuíam mulheres em seu quadro, que em média as mulheres compõem até $20 \%$ das cadeiras dos conselhos e que, das empresas listadas no Novo Mercado, apenas $4 \%$ possuem mulheres nos conselhos de administração. Na Suécia, país que lidera o ranking de empresas que adotam as melhores práticas de governança corporativa - no mínimo uma mulher no conselho de cada empresa -, a média é de $22 \%$ de mulheres ocupando cargos no conselho (IBGC, 2009).

Após a divulgação destes dados, foram implementadas iniciativas, no Brasil, para a inserção de uma maior proporção de número mulheres em assentos dos conselhos de administração (MARGEM, 2013), contudo, a desigualdade de gênero ainda está evidente na ascensão das mulheres aos cargos de alto escalação, tanto no Brasil como em outros países (MADALOZZO, 2011; RAMDHONY; OOGARAH-HANUMAN; SOMIR, 2013; SOUZA; VOESE; ABBAS, 2015; PERRYMAN; FERNANDO; TRIPATHY, 2016).

Com base nas informações obtidas pelo $\operatorname{IBGC}(2009,2011)$, tem-se a inferência de que nos dias atuais, ainda há presença de glass ceiling, barreira invisível que impede o aumento no número de mulheres no conselho de administração das empresas do Brasil e da Suécia. Nesse caso, sugere-se a incidência do glass ceiling ocorre por meio da presença de homens, que são responsáveis, na maioria das vezes, pela indicação e aprovação dos membros do conselho de administração, e assim, criam entre si uma proteção, renegando a inserção das mulheres.

A incidência de glass ceiling pode ser observada simplesmente pela existência de desigualdade de gênero com relação a remuneração, cargos de alto escalão, dentre outros fatores. Desse modo, não uma única forma para a mensuração do glass ceiling, mas de maneira subjetiva, é possível inferir sua incidência pela existência de desigualdade de gênero em determinados contextos organizacionais, em que os homens tomam decisões que limitam o acesso das mulheres a determinados cargos. Portanto, mesmo as mulheres tenham alta experiência profissional e acadêmica, são limitadas a assumir determinados cargos e a obter salários compatíveis aos dos homens.

Diante das evidências, pode-se inferir que o glass ceiling prevalece nos altos cargos da hierarquia corporativa, principalmente no que tange ao conselho de administração e a diretoria executiva das companhias. Contudo, indícios já tem apontado que a maior proporção de mulheres na ocupação destes cargos, pode ser fator preponderante para o alcance de resultados organizacionais e, portanto, comprovar estes argumentos pode ser útil na busca pela igualdade de gênero nos cargos de alto escalão. Assim, a próxima secção aborda sobre o panorama do impacto da desigualdade de gênero no desempenho organizacional, discutindo teórica e empiricamente as preposições úteis para discussões posteriores. 


\subsection{Glass Ceiling nos Cargos de Topo e seu Impacto no Desempenho Organizacional}

A presença das mulheres nos conselhos corporativos traz, muitas vezes, uma nova perspectiva sobre questões complexas, e isso pode auxiliar na formulação de estratégias e na resolução de problemas, melhorando assim, o desempenho da firma (DEWATRIPONT; JEWITT; TIROLE, 1999; WESTPHAL; MILTON, 2000). Nessa direção, características dos conselhos de administração, como a estrutura e a presença das mulheres em cargos superiores, foram analisadas por diversos estudos, tais como Wolfers (2006), Smith, Smith e Verner (2006), Francoeur, Labelle e Desgagne (2008), Nielsen e Huse (2010), Fraga e Silva (2012) e Almeida, Klotzle e Pinto (2013), Huang e Kisgen (2013), Faccio, Marchica e Mura (2016), Perryman, Fernando e Tripathy (2016) e Santos et al. (2017).

Wolfers (2006) buscou relacionar os retornos das ações ao gênero dos CEOs. O estudo utilizou dados da base Standard \& Poor's e indicadores no período de 1992 a 2004 . Os resultados indicaram que não há diferenças, significativa no retorno das ações, que possam ser explicadas pelo gênero dos CEOs. Smith, Smith e Verner (2006) analisaram a conexão entre diversidade de gênero na gestão e o desempenho da empresa. Utilizaram uma amostra das 2.500 maiores empresas dinamarquesas no período de 1993 a 2001. Os resultados indicaram que a proporção de mulheres em cargos de direção exerce efeito positivo no desempenho da empresa, contudo, esse efeito também depende da qualificação acadêmica e profissional.

Francoeur, Labelle e Desgagne (2008) analisaram se a participação das mulheres no conselho de administração e na diretoria/gerência impactam no desempenho financeiro das 500 maiores empresas canadenses. Os resultados indicam que as empresas que operam em ambientes complexos geram retornos positivos anormais e significativos quando possuem uma alta proporção de diretores do sexo feminino. As empresas com alta proporção de mulheres na diretoria executiva e no conselho geram valor suficiente para manter a organização com retornos normais no mercado de ações. As evidências sugerem que o melhor desempenho financeiro pode ser resultado da presença feminina nos conselhos corporativos e nas diretorias.

Já o estudo de Nielsen e Huse (2010) investigou a contribuição das mulheres para os conselhos de administração de 201 empresas norueguesas. Os autores concluíram que a proporção de mulheres na gestão está associada ao controle estratégico do conselho. Constataram que a presença de mulheres na diretoria provoca efeito positivo sobre a eficácia do conselho, pelo aumento nas atividades e redução nos conflitos internos. Fraga e Silva (2012), averiguando as empresas sem controle majoritário, nos anos de 2005 a 2009, argumentaram que, apesar da escassa presença das mulheres nos conselhos, as empresas que apresentaram melhor desempenho possuem, no mínimo, um integrante do sexo feminino no conselheiro.

Almeida, Klotzle e Pinto (2013) avaliaram se a composição dos conselhos afeta o valor e o desempenho das empresas do setor de energia elétrica. Utilizaram dados secundários em uma amostra de 38 companhias de grande porte, no período de 2005 a 2010. Os resultados indicam que o tamanho do conselho de administração, a sua independência e o percentual de mulheres que o compõem não apresentam relação positiva com o desempenho.

Huang e Kisgen (2013) pesquisaram se diferenças de gênero dos CFOs (Chief Financial Officer) afetam decisões empresariais financeiras e de investimento. Os autores descobriram que as companhias sob o controle de CFOs mulheres crescem mais lentamente do que as controladas por CFOs masculinos e que as CFOs femininas são menos propensas a fazer um número significativo de aquisições. Ademais, constataram que as diretoras financeiras são menos dispostas a emitir dívida e colocam limites mais amplos nas estimativas de ganhos. Essas evidências sugerem que os homens exibem relativo excesso de confiança na tomada de decisão em comparação com as mulheres, e que elas são mais avessas aos riscos. 
Faccio, Marchica e Mura (2016) estudaram como o gênero do CEO (Chief Executive Officer) se relacionava com as decisões de risco (alavancagem, ROA e probabilidade de sobrevivência) das companhias, no período entre 1999 a 2009, com uma amostra envolvendo 18 países. Os autores concluíram que as empresas administradas por CEO`s mulheres tendem a fazer opções menos arriscadas de financiamento e investimento, do que as empresas similares dirigidas pelos CEO's do sexo masculino.

Perryman, Fernando e Tripathy (2016) investigaram o impacto da diversidade de gênero em equipes de topo no desempenho, risco da firma e remuneração dos executivos. Os resultados sugerem que a diversidade de gênero nas equipes de topo oferece menor risco e melhor desempenho para as firmas. Por sua vez, as executivas do gênero feminino apresentam menor remuneração em comparação aos homens que assumem os cargos de mesmo nível. Por fim, Santos et al. (2017) buscaram relacionar o nível de capital de terceiros, a longo e curto prazo, e a sua relação com a proporção de mulheres no conselho de administração das empresas. Concluíram que a presença feminina no conselho de administração reduz o índice de endividamento, reforçando novamente, a aversão ao endividamento por parte das mulheres.

Em um oposto, alguns estudos têm indicado um efeito negativo para as corporações com maior presença das mulheres no conselho de administração, sendo eles: Shrader, Blackburn e Iles (1997), Lee e James (2007), Adams e Ferreira (2009) e Dobbin e Jung (2011), além de estudos nacionais, como os de Martins et al., (2012) e Margem (2013).

Shrader, Blackburn e Iles (1997) investigaram a relação entre a percentagem de membros do sexo feminino no conselho e o desempenho das organizações, o qual é medido pelo retorno sobre o ativo e retorno sobre o patrimônio líquido, para uma amostra de 200 empresas listadas pela Fortune 500. Os resultados indicam uma relação negativa entre a percentagem de mulheres presentes no conselho e o desempenho das organizações.

Lee e James (2007) verificaram se as reações de acionistas eram modificadas diante dos anúncios de altos executivos, com destaque aos possíveis efeitos do gênero. A análise considerou os anúncios de altos executivos das empresas da Fortune 500 no período de 1990 a 2000. Os resultados elucidam que as reações de investidores aos anúncios de CEOs do sexo feminino eram significativamente mais negativas que aos de seus colegas do sexo masculino.

Adams e Ferreira (2009), utilizando uma amostra de empresas britânicas, sugerem que a participação das mulheres no conselho de administração causa efeitos adversos sobre o desempenho corporativo, como no preço das ações que é estabelecido pelo comportamento dos participantes do mercado; porém, não provoca efeito em medidas objetivamente estabelecidas, tais como na rentabilidade, que é obtida utilizando-se as normas contábeis.

Dobbin e Jung (2011) examinaram, em 2.500 empresas dinamarquesas, se os conselhos estão atentos às exigências dos investidores institucionais para uma maior diversidade de gênero no conselho de administração. Os resultados corroboram a proposição de que o preconceito relativo ao gênero afeta o preço das ações. De acordo com os resultados, empresas que nomeiam diretoras apresentam efeitos negativos sobre o valor das ações e nenhum efeito sobre os lucros, ou seja, sobre indicadores de rentabilidade tradicionais.

Martins et al. (2012) realizaram, no período de 2008 e 2009, um estudo em bancos brasileiros que negociam ações em bolsa. Os resultados revelam que os bancos que possuem maior proporção de mulheres do conselho de administração apresentam uma correlação negativa com o desempenho financeiro. Para os autores, o resultado pode estar vinculado à atuação feminina recente na gestão das organizações.

Margem (2013) buscou averiguar se a participação das mulheres nos conselhos e na diretoria afeta o valor e o desempenho das empresas brasileiras. Para tanto, analisou 658 companhias brasileiras, no período de 2002 a 2009. Os resultados indicaram não haver uma relação significativa entre a participação das mulheres no conselho e em cargos de diretoria e o 
valor das empresas, sinalizando a ocorrência de uma relação negativa entre a presença de mulheres no conselho e o desempenho das empresas.

De maneira geral, os estudos de Smith, Smith e Verner (2006), Francoeur, Labelle e Desgagne (2008) e Fraga e Silva (2012), não utilizaram da abordagem do glass ceiling para explicar seus achados, contudo, contribui-se com tal inserção, em que a participação das mulheres impactou no melhor desempenho organizacional e, portanto, quando não há presente de glass ceiling a empresa tendem a obter melhor desempenho. Os achados demonstram que o mercado tem sido contrário à práticas discriminatórios contidas no glass ceiling, visto que valorizam empresas que contém maior proporção de mulheres ocupam altos cargos de gestão.

Por outro lado, os estudos de Shrader, Blackburn e Iles (1997), Lee e James (2007), Adams e Ferreira (2009) e Dobbin e Jung (2011), Martins et al., (2012) e Margem (2013) ajudaram a atenuar a ocorrência de glass ceiling, pela demonstração de que a desigualdade de gênero pode causar desempenho organizacional inferior. As evidências fazem emergir o pensamento de que os homens, quando responsáveis pela indicação e aprovação de membros do conselho de administração, podem criar tendências há barreiras invisíveis (impedimentos que na prática não existem), para a não inserção de mulheres, visto a possibilidade de obter desempenho incompatível com suas expectativas.

Além disso, os estudos que demonstraram um desempenho inferior pela maior participação feminina nos cargos de topo, como o caso de Lee e James (2007), Adams e Ferreira (2009), Dobbin e Jung (2011) e Margem (2013), focalizaram nas expectativas de investidores através da observação na variação do preço das ações. Caso seja comprovada a evidência de que as mulheres auxiliam na melhoria do desempenho econômico nas corporações, a visão dos investidores pode ser alterada e os resultados contraditórios sobre o preço das ações fique menos evidente. Diante do exposto, se faz necessário apresentar as métricas que neste estudo serão utilizadas para determinar a avaliação do desempenho financeiro e econômico.

\subsection{Avaliação do Desempenho Financeiro e Econômico}

A avaliação de desempenho das empresas possui várias dimensões inter-relacionadas em função da amplitude (funcional, divisional, global), do tempo (curto, médio e longo) e da natureza (operacional, econômico e financeiro) (CATELLI, 1999). Para avaliação do desempenho financeiro e econômico, existe um conjunto de indicadores disponíveis. Ainda que o conjunto de indicadores que cada órgão avaliador utiliza dependa do objetivo da análise, o resultado a ser alcançado sempre será o de classificar as empresas conforme sua capacidade financeira (BEZERRA; CORRAR, 2006).

Os administradores, assim como os acionistas, preocupam-se com todos os aspectos financeiros da empresa e buscam construir índices financeiros úteis tanto aos proprietários como aos credores (GITMAN, 2004). Matarazzo (1995) sugere que, para a avaliação do desempenho financeiro das empresas, seja utilizada uma quantidade entre 11 a 14 indicadores, porque o acréscimo de índices pode reduzir o benefício informacional.

Matarazzo (2003) pondera que o exame das demonstrações contábeis pode ser dividido em análise da situação financeira e análise da situação econômica. Os índices podem ser classificados em grupos, sendo financeiros (índices de estrutura de capital e índices de liquidez) e econômicos (índices de rentabilidade). Assim, os índices de estrutura de capital mostram as decisões financeiras, em termos de obtenção e aplicação de recursos. Já os índices de liquidez expõem a base da situação financeira da organização. Os índices de rentabilidade ou resultados, por seu turno, apresentam qual a rentabilidade dos capitais investidos, demonstrando quanto os investimentos renderam e o êxito econômico da organização (MATARAZZO, 2003). 
Para Silva (2008), há quatro grupos de indicadores financeiros, quais sejam: índices de lucratividade e desempenho (índices de retorno ou rentabilidade); índices de prazos médios (capital de giro, afetando a lucratividade, a liquidez e o endividamento); índices de estrutura de capitais; índices de liquidez (imobilização do patrimônio líquido, participação de capitais de terceiros, composição do endividamento).

Os modelos de análise de balanços fornecem uma compreensão geral do desempenho como um fator multidimensional, na qual é necessário considerar uma análise conjunta dos indicadores (KASSAI, 2002). Bezerra e Corrar (2006) ponderam que os indicadores financeiros são utilizados para se fazer comparações entre empresas ou mesmo unidades de uma mesma companhia. As medidas de desempenho são um elemento integrante do ciclo de planejamento e controle e possibilitam quantificar a eficiência e a eficácia da organização (NEELY et al., 1997). Essa medição fornece um meio de capturar dados de desempenho que podem ser usados para auxiliar na tomada de decisão. A definição dessas medidas envolve recursos humanos e sofre influência dos aspectos comportamentais (NEELY et al., 1997).

Este capítulo auxilia na determinação dos indicadores utilizados na avaliação do desempenho financeiro e econômico das empresas, conforme estabelecido pela metodologia da pesquisa, para enfim, elaborar uma associação entre a desigualdade de gênero nos cargos de topo e o alcance de desempenho corporativo satisfatório.

\section{Metodologia da Pesquisa}

Para identificar o Glass Ceiling nos Conselhos Corporativos e seu impacto no desempenho organizacional, a presente pesquisa é delineada, quanto aos objetivos, como descritiva, por observar variáveis sem manipulá-las. No tocante à abordagem do problema, caracteriza-se como pesquisa quantitativa, pois identifica a influência das variáveis com a aplicação da regressão, e a coleta de dados é documental.

A população do estudo é composta pelas empresas brasileiras de capital aberto que compõem o índice IBrX 100. A escolha foi justificada por estas empresas estarem entre as cem melhores classificadas quanto ao índice de negociabilidade, determinado nos 12 meses precedentes à reavaliação, bem como negociadas, em maior percentual, nos pregões ocorridos nos 12 meses anteriores à formação da carteira. Desse modo, essas empresas constituem-se as mais relevantes e representativas para o mercado de capitais brasileiro e, portanto, os achados desta amostra podem oferecer indicativos úteis e generalizáveis ao restante das empresas brasileiras.

A amostra para fins do estudo é caracterizada como não probabilística e intencional. Após a exclusão das empresas do setor financeiro, por possuírem características particulares específicas e que fogem da proposta da pesquisa, e também de empresas que não ofereceram todos os dados suficientes para o estudo, a amostra final foi constituída de 61 empresas.

Para composição das variáveis, os dados foram coletados a partir do Formulário de Referência do ano de 2014 e do banco de dados da Economática ${ }^{\circledR}$. Após, foram tabulados em planilhas eletrônicas para cálculo das variáveis estudadas. As variáveis dependentes e independentes utilizadas nesta pesquisa estão apresentadas no Quadro 1. 
Quadro 1 - Variáveis dependentes e independentes

\begin{tabular}{|c|c|c|}
\hline \multicolumn{3}{|c|}{ Variáveis dependentes } \\
\hline Indicador & Fórmula & Autores Base \\
\hline Valor de Mercado (VM) & Valor Mercado & $\begin{array}{c}\text { Wolfers (2006); Lee e James (2007); } \\
\text { Francoeur, Labelle e Desgagne (2008); } \\
\text { Martins et al. (2012) }\end{array}$ \\
\hline Preço da ação (PA) & Fechamento & $\begin{array}{c}\text { Wolfers (2006); Lee e James (2007); } \\
\text { Francoeur, Labelle e Desgagne (2008); } \\
\text { Adams e Ferreira (2009); Dobbin e Jung } \\
\text { (2011) }\end{array}$ \\
\hline Retorno do Ativo (ROA) & LucroLíquido & Shrader, Blackburn e Iles (1997); Smith, \\
\hline 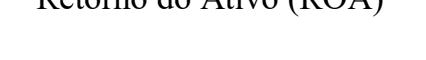 & AtivoTotal & e Pinto (2013); Margem (2013) \\
\hline Retorno do Patrimônio & LucroLíquido & $\begin{array}{l}\text { Shrader, Blackburn e Iles (1997); Smith, } \\
\text { Smith e Verner (2006); Adams e Ferreira }\end{array}$ \\
\hline Líquido (ROE) & $\overline{\text { PatrimônioLíquido }}$ & $\begin{array}{l}\text { (2009); Dobbin e Jung (2011); Almeida, } \\
\text { Klotzle e Pinto (2013); Margem (2013) }\end{array}$ \\
\hline Retorno sobre as Vendas & LucroLíquido & Smith, Smith e Verner (2006); Almeida, \\
\hline$(\mathrm{ROS})$ & $\overline{\text { VendasLíquidas }}$ & Klotzle e Pinto (2013); Margem (2013) \\
\hline \multicolumn{3}{|c|}{ Variáveis Independentes } \\
\hline Indicador & Fórmula & Autores Base \\
\hline $\begin{array}{l}\text { Tamanho do Conselho de } \\
\text { Administração (TCA) }\end{array}$ & $\begin{array}{l}\text { Total de membros do Conselho } \\
\text { de Administração }\end{array}$ & $\begin{array}{c}\text { Gondrige, Clemente e Espejo (2012); } \\
\text { Fraga e Silva (2012) }\end{array}$ \\
\hline $\begin{array}{l}\text { Tamanho do Conselho Fiscal } \\
\text { (TCF) }\end{array}$ & $\begin{array}{l}\text { Total de membros do Conselho } \\
\text { Fiscal }\end{array}$ & $\begin{array}{c}\text { Gondrige, Clemente e Espejo (2012); } \\
\text { Fraga e Silva (2012) }\end{array}$ \\
\hline Total de Diretores (TDR) & Total de membros Diretores & $\begin{array}{c}\text { Gondrige, Clemente e Espejo (2012); } \\
\text { Fraga e Silva (2012) }\end{array}$ \\
\hline $\begin{array}{l}\text { Percentual de Mulher } \\
\text { Conselho de Administração } \\
\text { (PMCA) }\end{array}$ & $\begin{array}{c}\mathrm{N}^{\mathrm{o}} \text { de mulheres no Conselho/ } \\
\text { Total de membros do Conselho } \\
\text { Administração }\end{array}$ & $\begin{array}{c}\text { Wolfers (2006); Smith e Verner (2006); } \\
\text { Adams e Ferreira (2009); Martins et al. } \\
\text { (2012); Almeida, Klotzle e Pinto (2013); } \\
\text { Margem (2013) }\end{array}$ \\
\hline $\begin{array}{c}\text { Percentual de Mulher } \\
\text { Conselho Fiscal (PMDR) }\end{array}$ & $\begin{array}{l}\mathrm{N}^{\mathrm{o}} \text { de mulheres no Conselho/ } \\
\text { Total de membros do Conselho } \\
\text { Fiscal }\end{array}$ & $\begin{array}{c}\text { Wolfers (2006); Smith, Smith e Verner } \\
\text { (2006) } \\
\text { Almeida, Klotzle e Pinto (2013); } \\
\text { Margem (2013) }\end{array}$ \\
\hline $\begin{array}{l}\text { Percentual de Mulher na } \\
\text { Diretoria (PMCF) }\end{array}$ & $\begin{array}{l}\mathrm{N}^{\circ} \text { de mulheres na Diretoria/ } \\
\text { Total de membros diretores }\end{array}$ & $\begin{array}{l}\text { Wolfers (2006); Smith, Smith e Verner } \\
\text { (2006); Lee e James (2007); Dobbin e } \\
\text { Jung (2011); Almeida, Klotzle e Pinto } \\
\text { (2013); Margem (2013) }\end{array}$ \\
\hline Tamanho (TAM) & Ln (Ativo Total) & Variável de Controle \\
\hline
\end{tabular}

Fonte: Dados da pesquisa.

Com o uso das variáveis expostas no Quadro 1, foram elaborados os modelos de regressão Linear Múltipla. Desse modo, seguem as equações utilizadas no estudo.

$$
\begin{aligned}
& V M=\beta_{0}+\beta_{1} T C A+\beta_{2} T D R+\beta_{3} T C F+\beta_{4} P M C A+\beta_{5} P M D R+\beta_{6} P M C F+\beta_{7} T A M+\varepsilon(1) \\
& P A=\beta_{0}+\beta_{1} T C A+\beta_{2} T D R+\beta_{3} T C F+\beta_{4} P M C A+\beta_{5} P M D R+\beta_{6} P M C F+\beta_{7} T A M+\varepsilon(2) \\
& R O A=\beta_{0}+\beta_{1} T C A+\beta_{2} T D R+\beta_{3} T C F+\beta_{4} P M C A+\beta_{5} P M D R+\beta_{6} P M C F+\beta_{7} T A M+\varepsilon(3) \\
& R O E=\beta_{0}+\beta_{1} T C A+\beta_{2} T D R+\beta_{3} T C F+\beta_{4} P M C A+\beta_{5} P M D R+\beta_{6} P M C F+\beta_{7} T A M+\varepsilon(4) \\
& R O S=\beta_{0}+\beta_{1} T C A+\beta_{2} T D R+\beta_{3} T C F+\beta_{4} P M C A+\beta_{5} P M D R+\beta_{6} P M C F+\beta_{7} T A M+\varepsilon(5) \\
& \text { Onde: }
\end{aligned}
$$

VM: Valor de Mercado; PA: Preço da Ação; ROA: Retorno do Ativo; ROE: Retorno do Patrimônio Líquido; ROS: Retorno sobre as Vendas; TCA: Tamanho do Conselho de Administração; TCF: Tamanho do Conselho Fiscal; TDR: Total de Diretores; PMCA: Percentual de Mulher Conselho de Administração; PMDR: Percentual de Mulher na Diretoria; PMCF: Percentual de Mulher Conselho Fiscal; TAM: Tamanho da empresa; $\varepsilon$ : Erro. 
Em conformidade com as equações que serão utilizadas para execução do objetivo da pesquisa, optou-se pela utilização do método de Regressão Linear Múltipla, o qual consiste em verificar a existência de dependência estatística de uma variável dependente em relação a uma ou mais variáveis independentes. Para tal, a análise foi realizada por intermédio do software estatístico SPSS.

\section{Análise dos Dados e interpretação dos Resultados}

Para responder ao objetivo da pesquisa, que é identificar a incidência de Glass Ceiling nos cargos de board e seu impacto no desempenho organizacional das companhias brasileiras de capital aberto listadas no índice IBrX 100, primeiramente se apresenta a estatística descritiva das variáveis, conforme Tabela 1.

Verifica-se que, no que tange aos índices econômicos, a média do valor de mercado das empresas foi de R \$ 166.077.965. O preço da ação variou entre o mínimo de R \$ 0,58 e o máximo de $\mathrm{R} \$ 93,50$ no fechamento de 31/12/2014, com uma média para as empresas de R \$20,22. Quanto aos indicadores financeiros, a média do Retorno sobre o Ativo das empresas foi de 0,029, Retorno sobre o Patrimônio Líquido foi de 0,068 e Retorno sobre as Vendas foi de 0,065.

Tabela 1 - Estatística descritiva das variáveis

\begin{tabular}{c|c|c|c|c|c|}
\hline Variáveis & $\mathbf{N}$ & Mínimo & Máximo & Média & Desvio Padrão \\
\hline VM & 61 & 2.577 .311 & 2.281 .064 .382 & 166.077 .965 & 330.524 .290 \\
\hline PA & 61 & 0,58 & 93,50 & 20,22 & 16,68 \\
\hline ROA & 61 & $-0,945$ & 0,258 & 0,029 & 0,139 \\
\hline ROE & 61 & $-1,613$ & 0,747 & 0,068 & 0,309 \\
\hline ROS & 61 & $-2,060$ & 0,605 & 0,065 & 0,318 \\
\hline TAM & 61 & 13,875 & 19,550 & 16,469 & 1,137 \\
\hline TCA & 61 & 2,00 & 29,00 & 9,57 & 5,52 \\
\hline TDR & 61 & 2,00 & 13,00 & 6,13 & 2,32 \\
\hline TCF & 61 & 3,00 & 13,00 & 7,01 & 2,18 \\
\hline PMCA & 61 & 0,00 & 0,40 & 0,10 & 0,11 \\
\hline PMD & 61 & 0,00 & 0,50 & 0,08 & 0,12 \\
\hline PMCF & 61 & 0,00 & 0,67 & 0,11 & 0,15 \\
\hline
\end{tabular}

Fonte: Dados da pesquisa.

No que se refere os cargos de board, os resultados indicam que no Tamanho do Conselho de Administração (TCA), há uma variação entre o mínimo de 2 membros e máximo de 29 membros, com uma média nas empresas de 9,57 membros no conselho de administração. No que concerne ao Tamanho da Diretoria (TDR), há uma variação de no mínimo 2 e máximo de 13 diretores, com uma média de 6,13 diretores. O Tamanho do Conselho Fiscal (TCF) é formado por no mínimo 3 e máximo 13 membros, com uma média de 7,01 membros.

Quanto à variável da diversidade de gênero obtida pela Proporção de Mulheres no Conselho de Administração (PMCA), constatam-se conselhos de administração sem participação feminina (mínimo 0,00) e conselhos com participação feminina de no máximo $40 \%$ com relação ao total de membros. A média de mulheres que ocupam cargos no conselho de administração das empresas brasileiras foi de $10 \%$, o que sinaliza a incidência de Glass Ceiling. Esse achado é consistente com a inferência do IBGC (2011), que constatou que apenas $7,7 \%$ dos cargos do conselho de administração são ocupados pelas mulheres. Ressalta-se que a amostra desta pesquisa é diferente da utilizada pelo IBGC (2011) e, portanto, não é possível inferir que houve uma elevação - 7,7\% para $10 \%$ - na participação das mulheres no conselho. 
No que concerne à Proporção de Mulheres que Ocupam Cargos de Diretoria (PMD), verificou-se que há empresas sem diretores do gênero feminino (mínimo de 0,0 ) e empresas com, no máximo, $50 \%$ dos diretores de gênero feminino. Em média, a presença de diretoras nas empresas estudadas foi de $8 \%$. Por fim, em relação à Proporção de Mulheres no Conselho Fiscal (PMCF), igualmente se contata que existem conselhos fiscais sem a participação de mulheres (mínimo 0,00) e conselhos com a participação de no máximo 67\%. A média de mulheres que ocupam cargos no conselho fiscal das empresas brasileiras foi de $11 \%$. Tal achado evidencia a presença do Glass Ceiling nos conselhos fiscais das empresas brasileiras. Conclui-se que, em comparação aos conselhos de administração e às diretorias, o conselho físcal é o mais suscetível para o ingresso das mulheres, mesmo que de maneira ainda limitada.

Em suma, a estatística descritiva sugere a presença de uma barreira invisível criada para que as mulheres não ocupem cargos dos mais variados níveis da alta hierarquia. Nesse caso, foi encontrada a barreira invisível (Glass Ceiling) nos cargos do conselho de administração, diretoria e conselho fiscal. De maneira geral, o achado apresenta consistência com as argumentações de Daily, Certo Dalton (1999), Gutner (2001), Wearing e Wearing (2004) e Blau e Devaro (2007), de que os homens, geralmente, preservam alguns cargos de alto nível estratégico, não permitindo que seja incluída a presença feminina. Além disso, os homens estão preocupados com a preservação dos cargos de topo, mas também há inquietação com relação aos salários, que ficam mais homogêneos pela inserção das mulheres nos cargos de maior remuneração, conforme preconizado por Perryman, Fernando e Tripathy (2016).

Além disso, conclui-se que como o conselho de administração, diretoria e conselho fiscal tem sido ocupado majoritariamente por representantes masculinos, os mesmos tendem a escolher outros ocupantes para os cargos que representem ao máximo seu próprio perfil, fazendo com que as mulheres tenham maior resistência à promoção.

Posteriormente à análise da estatística descritiva, tem-se a regressão linear múltipla que visou identificar a influência da presença feminina nos cargos de board sobre o desempenho organizacional. Assim, primeiramente, apresenta-se a influência dos cargos de board nos índices financeiros Valor de Mercado (VM) e Preço da Ação (PA).

Para aumentar a confiabilidade dos dados e testar a autocorrelação, aplicou-se o teste de Durbin-Watson, no qual resultou em um valor de 2,13 e para o PA um valor de 1,91, ambos próximos de 2,00, o que sugere que os modelos não apresentam problemas de autocorrelação dos resíduos. Para testar a multicolinearidade, utilizou-se o Fator de Inflação da Variância, que foi calculado para cada variável independente de cada modelo, apresentando variação de 1,085 a 1,304, valores abaixo de 10, os quais demonstram que as variáveis não são multicolineares.

Os achados sobre a incidência de glass ceiling nos cargos de board e seu impacto do desempenho econômico das empresas brasileiras do índice IBrX 100 são apresentados de maneira detalhada na Tabela 2, conforme segue.

Genericamente, observa-se que o modelo da diversidade de gênero dos cargos de board (o qual implica na incidência do glass ceiling) impacta em 36,9\% o valor de mercado das organizações, apresentando significância ao nível de 5\%, ou seja, 0,001. Tal resultado indica, que os conselhos corporativos influenciam o valor de mercado das organizações.

Além disso, o modelo indica que TDR, TAM e PMD são significativas ao nível de 5\%. O Tamanho da Diretoria (TDR), medido pelo número total de diretores, impacta positivamente o valor de mercado das organizações, isto é, quanto maior for o número de diretores, maior será o valor de mercado das organizações, com significância ao nível de 5\% (0,038). Ademais, verifica-se que o Tamanho da Empresa (TAM) impacta no valor de mercado, ou seja, quanto maior for a organização, maior será seu valor de mercado, ao nível de significância de $5 \%$ $(0,000)$. O achado corrobora as inferências de Gondrige, Clemente e Espejo (2012), pelos quais o número de membros no conselho impacta a valorização das empresas perante o mercado. 
Tabela 2 - Influência da diversidade de gênero dos cargos de board no desempenho econômico

\begin{tabular}{|c|c|c|c|c|}
\hline \multirow{3}{*}{ Variáveis } & \multicolumn{4}{|c|}{ Índices Econômicos } \\
\hline & \multicolumn{2}{|c|}{ VM } & \multicolumn{2}{|c|}{ PA } \\
\hline & Coefic. & Sig. & Coefic. & Sig. \\
\hline (Constante) & $-7,168$ & 0,000 & 2,855 & 0,935 \\
\hline TCA & 0,016 & 0,482 & $-0,289$ & 0,530 \\
\hline TDR & 0,104 & $0,038^{*}$ & 0,265 & 0,792 \\
\hline TCF & $-0,078$ & 0,154 & $-0,750$ & 0,497 \\
\hline TAM & 0,420 & $0,000^{*}$ & 1,328 & 0,545 \\
\hline PMCA & 0,014 & 0,990 & 1,355 & 0,952 \\
\hline PMD & 2,076 & $0,045^{*}$ & $-9,471$ & 0,648 \\
\hline PMCF & $-1,342$ & 0,116 & 21,927 & 0,206 \\
\hline Durbin-Watson & \multicolumn{2}{|c|}{2,130} & \multicolumn{2}{|c|}{1,910} \\
\hline $\mathrm{R}^{2}$ & \multicolumn{2}{|c|}{0,369} & \multicolumn{2}{|c|}{0,055} \\
\hline $\mathrm{R}^{2}$ Ajustado & \multicolumn{2}{|c|}{0,286} & \multicolumn{2}{|c|}{$-0,070$} \\
\hline Sig. do Modelo & \multicolumn{2}{|c|}{$0,001 *$} & \multicolumn{2}{|c|}{0,874} \\
\hline
\end{tabular}

Fonte: Dados da pesquisa.

Ademais, no que se refere à diversidade de gênero, constata-se que a única variável que apresentou significância ao nível de 5\% com o valor de mercado foi a Proporção de Mulheres na Diretoria (PMD). É possível concluir que, quanto maior for o número de mulheres na diretoria, maior será o valor de mercado das organizações, com nível de significância de 0,045 e, portanto, quando não há incidência de glass ceiling as empresas tendem a obter um melhor valor de mercado. Conclui-se que a sociedade e investidores valorizam, com maior ênfase, as empresas que promovem a participação das mulheres nos cargos de topo e que buscam inibir as ações dos homens em propagar o glass ceiling.

Conclui-se que fica cada vez mais evidente que o cuidado com a desigualdade de gênero tem sido decisivo para o desempenho das organizações, sendo que este tipo de cuidado agrega valor à imagem da empresa frente as relações com parceiros, consumidores e sociedade, por demonstrar preocupação com as demandas da própria sociedade, fatores que foram comprovados pela valorização do mercado às empresas com maior presença das mulheres nos cargos de alto escalão corporativo.

Por outro lado, verifica-se que a diversidade de gênero nos cargos de board apresentou relação com o preço das ações, em que no modelo nenhuma das variáveis apresentou significância ao nível de 5\%. De modo geral, o preço das ações não é impactado pelo tamanho do conselho de administração, total de diretores, tamanho do conselho fiscal, tamanho da empresa, percentual de mulheres no conselho de administração, percentual de mulheres na diretoria e percentual de mulheres no conselho fiscal. Tais resultados contrariam os estudos de Lee e James (2007), Adams e Ferreira (2009), Dobbin e Jung (2011) e Margem (2013), nos quais evidenciou-se a existência de um efeito negativo entre a diversidade de gênero nos cargos de board e o preço das ações nas organizações, contrariando também o fato da não incidência de glass ceiling impactar negativamente no desempenho organizacional.

Tais resultados sugerem que os investidores não criam barreiras (Glass Ceiling) à valorização das empresas que possuem maior número de mulheres na diretoria, visto o aumento na valorização de mercado das empresas que possuem mulheres no alto escalão e também por não ter sido encontrado relação negativa com preço das ações. Diante do achado, pode-se inferir que são os indivíduos internos à organização que criam barreiras invisíveis para a ascensão das mulheres nos cargos de alto escalão. Para tanto, as empresas devem considerar as proposições mercadológicas e ampliar a discussão interna com relação a reduzir a desigualdade de gênero em cargos do alto escalão. 
Sobre as variáveis Proporção de Mulheres no Conselho de Administração (PMCA), Proporção de Mulheres no Conselho Fiscal (PMCF), Tamanho do Conselho de Administração (TCA) e Tamanho do Conselho Fiscal (TCF), as evidências não apresentam relação significativa com o Valor de Mercado (VM) das organizações.

Na sequência, a Tabela 3 identifica a incidência de glass ceiling nos cargos de board e seu impacto no desempenho financeiro das empresas brasileiras. Primeiramente, para aumentar a confiabilidade dos dados e testar a autocorrelação das variáveis ROA, ROE e ROS em relação às variáveis independentes, procedeu-se ao teste de Durbin-Watson, cujos resultados foram: para o ROA, o valor de 1,91; para o ROE, 2,14; e para o ROS, 1,80, todos próximos de 2,00. Isso sugere que, para os modelos, não há problemas de autocorrelação dos resíduos. Para testar a multicolinearidade, utilizou-se o Fator de Inflação da Variância, que foi calculado para cada variável independente de cada modelo, apresentando variação de 1,085 a 1,304, valores abaixo de 10, os quais demonstram que as variáveis não apresentam multicolinearidade.

Tabela 3 - Influência da diversidade de gênero dos cargos de board no desempenho financeiro

\begin{tabular}{|c|c|c|c|c|c|c|}
\hline \multirow{3}{*}{ Variáveis } & \multicolumn{6}{|c|}{ Índices Financeiros } \\
\hline & \multicolumn{2}{|c|}{ ROA } & \multicolumn{2}{|c|}{ ROE } & \multicolumn{2}{|c|}{ ROS } \\
\hline & Coefic. & Sig. & Coefic. & Sig. & Coefic. & Sig. \\
\hline (Constante) & $-0,512$ & 0,068 & $-1,199$ & 0,044 & $-0,963$ & 0,138 \\
\hline TCA & $-0,001$ & 0,768 & $-0,003$ & 0,674 & $-0,002$ & 0,804 \\
\hline TDR & 0,015 & 0,059 & 0,037 & $0,030 *$ & 0,026 & 0,162 \\
\hline $\mathrm{TCF}$ & 0,013 & 0,129 & 0,030 & 0,106 & 0,033 & 0,108 \\
\hline TAM & 0,020 & 0,257 & 0,045 & 0,223 & 0,035 & 0,389 \\
\hline PMCA & 0,249 & 0,159 & 0,825 & $0,029 *$ & 0,315 & 0,440 \\
\hline PMD & 0,166 & 0,308 & 0,460 & 0,184 & 0,452 & 0,235 \\
\hline PMCF & 0,050 & 0,710 & 0,080 & 0,778 & 0,222 & 0,480 \\
\hline Durbin-Watson & \multicolumn{2}{|c|}{1,910} & \multicolumn{2}{|c|}{2,140} & \multicolumn{2}{|c|}{1,800} \\
\hline $\mathrm{R}^{2}$ & \multicolumn{2}{|c|}{0,176} & \multicolumn{2}{|c|}{0,245} & \multicolumn{2}{|c|}{0,139} \\
\hline $\mathrm{R}^{2}$ Ajustado & \multicolumn{2}{|c|}{0,067} & \multicolumn{2}{|c|}{0,146} & \multicolumn{2}{|c|}{0,026} \\
\hline Sig. do Modelo & \multicolumn{2}{|c|}{0,151} & \multicolumn{2}{|c|}{$0,029 *$} & \multicolumn{2}{|c|}{0,305} \\
\hline
\end{tabular}

* Nível de significância de 5\%.

Fonte: Dados da pesquisa.

Observa-se que o modelo da relação entre a diversidade de gênero nos cargos de board e retorno sobre patrimônio líquido (ROE) apresentou significância ao nível de 5\% $(0,29)$ e poder de explicação de $24,50 \%$. Todavia, os modelos da diversidade de gênero dos cargos de board referente ao retorno do ativo e retorno sobre as vendas não apresentaram significância.

$\mathrm{Na}$ análise específica do impacto da diversidade de gênero dos conselhos corporativos no retorno sobre patrimônio líquido (ROE), os resultados indicam que o Tamanho da Diretoria (TDR) impacta positivamente no ROE das organizações, ou seja, quanto maior for o número de diretores, maior será o ROE, com significância ao nível de 5\% $(0,030)$.

Além disso, os resultados indicam que a proporção de mulheres no conselho de administração influencia o ROE. Desse modo, quanto maior a participação das mulheres (menor incidência de glass ceiling) no conselho de administração, maior será o ROE. Esse resultado lança uma discussão sobre a desvinculação dos executivos às barreiras invisíveis criadas para dificultar a promoção das mulheres aos cargos estratégicos, visto que as mulheres, nesse meio, tendem a gerar resultados satisfatórios. É preciso que as organizações, gestores e tomadores de decisão tenham consciência de que o Glass Ceiling pode prejudicar os anseios organizacionais.

Resultados consistentes no tocante à melhoria do desempenho por indicadores financeiros em função da alta proporção de mulheres nos cargos de diretoria são apontados pelos estudos de Myers (2003), Wolfers (2006), Smith, Smith e Verner (2006), Francoeur, 
Labelle e Desgagne (2008), Nielsen e Huse (2010), Fraga e Silva (2012) e Almeida, Klotzle e Pinto (2013), Huang e Kisgen (2013), Faccio, Marchica e Mura (2016), Perryman, Fernando e Tripathy (2016) e Santos et al. (2017).

No entanto, nos indicadores de Retorno Sobre o Ativo (ROA) e de Retorno Sobre as Vendas (ROS), os resultados são contraditórios aos apontados pelos estudos acima, já que não foi possível confirmar que a diversidade de gênero nos conselhos impacta em tais indicadores. Ademais, não foram corroboradas as evidências expostas pelos estudos de Shrader, Blackburn e Iles (1997), Adams e Ferreira (2009), Dobbin e Jung (2011), que evidenciaram relação negativa entre a diversidade de gênero e o desempenho das organizações, porque, no caso do ROE, houve aumento em função da diversidade do gênero na diretoria e, nos demais indicadores, não foram encontradas evidências de relação significante.

No contexto das companhias brasileiras de capital aberta listadas no índice IBrX 100, os resultados revelaram que o Tamanho do Conselho de Administração (TCA), o Tamanho do Conselho Fiscal (TCF), o Tamanho da Empresa (TAM), a Proporção de Mulheres Diretoras (PMD) e a Proporção de Mulheres no Conselho Fiscal (TCF) não impactam o Retorno sobre o Patrimônio Líquido (ROE) das organizações investigadas. Tal achado contraria os estudos de Shrader, Blackburn e Iles (1997), Lee e James (2007), Adams e Ferreira (2009), Dobbin e Jung (2011), Martins et al., (2012) e Margem (2013), que constataram que uma maior proporção de mulheres no board resultaria em pior desempenho e desvalorização da empresa no mercado.

Com base nos resultados obtidos, nos quais não ocorreu relação negativa significante entre as variáveis independentes relacionadas à presença da mulher no board e as variáveis dependentes relacionadas ao desempenho econômico e financeiro, infere-se, por um lado, que o mercado não é sensível à desigualdade de gênero (incidência de glass ceiling), o que pode indicar que o Glass Ceiling ocorre com base nos interesses intraorganizacionais e nos homens buscarem proteção por temerem à perda de espaço.

Os resultados oferecem indícios para a governança corporativa aplicada ao mecanismo de monitoramento denominado conselho de administração. Portanto, o IBGC deveria exercer preocupação frente as empresas comprovadas com ampla desigualdade de gênero, fazendo com que as mesmas minimizem o glass ceiling com a finalidade de fazer com que o conselho de administração tenha, no mínimo, um pouco do feeling das mulheres nas reflexões sobre decisões estratégicas, operacionais e de assunção aos riscos.

Por outro lado, o fato de haver pouca variação significativamente positiva entre a Proporção de Mulheres na Diretoria e no Conselho de Administração com o Valor de Mercado e o ROE, respectivamente, pode implicar uma baixa pressão do mercado para promover a redução das práticas discriminatórias de gênero nos cargos de alto nível hierárquico organizacional. Os achados sinalizam que, como a proporção de mulheres em cargos superiores não gera um desempenho econômico e financeiro superior, pode haver uma tendência para o mercado manter o status quo de universalização das práticas discriminatórias relacionadas ao gênero, continuando a desenvolver o glass ceiling, como prática de interesse patriarcais.

Comprova-se que as mulheres traçam uma nova perspectiva sobre as decisões que envolvem a formulação de estratégias e a resolução de problemas que envolvem o alcance de melhor desempenho. Nielsen e Huse (2010) também já afirmaram que a proporção de mulheres na gestão está positivamente associada ao controle estratégico do conselho. Além disso, a presença de mulheres na diretoria provoca efeitos positivos sobre a eficácia do conselho, pelo aumento nas atividades e diminuição nos conflitos. Essa visão também parece ser transmitida pelo mercado, no qual valoriza as empresas com maior participação feminina.

Huang e Kisgen (2013), Faccio, Marchica e Mura (2016) e Santos et al. (2017) preconizam sobre a aversão ao risco por parte das mulheres e, portanto, as empresas com maior 
proporção de mulheres no conselho e na diretoria podem ter apresentado melhor desempenho porque teriam tendência a ser menos arriscadas em termos mercadológicos e de capital.

\section{Conclusões e Recomendações}

A pesquisa buscou identificar a incidência de glass ceiling nos cargos de board e seu impacto no desempenho organizacional das companhias brasileiras listadas no índice IBrX 100 da Bovespa. Conclui-se que os investidores institucionais não criam barreiras (Glass Ceiling) à valorização das empresas que possuem maior número de mulheres na diretoria (cargos do alto escalão). Nesse sentido, pode-se inferir que as barreiras invisíveis, à ascensão das mulheres, continuam presentes pela dominação dos indivíduos que atuam diretamente nas organizações (homens patriarcas), os quais possuem interesses particulares de proteção salarial e profissional.

No contexto de estudos sobre Glass Ceiling, os resultados contrariam os estudos de Dewatripont, Jewitt e Tirole (1999) e Westphal e Milton (2000), no sentido de que o Glass Ceiling ocorre sobre os próprios investidores institucionais, os quais criam barreiras internas invisíveis para a progressão de mulheres em cargos de gestão superior. Além disso, percebe-se que o comportamento dos envolvidos na governança da empresa, a partir das escolhas gerenciais, que incluem um modelo de gestão com pouca participação feminina, pode impactar na elaboração das informações contábeis, na definição das medidas de avaliação e, consequentemente, no desempenho da corporação.

A partir dos resultados do estudo, pressupõe-se que, quando não há incidência do Glass Ceiling nos cargos de diretoria, conselho de administração e fiscal, a empresa tende a apresentar desempenho melhor quando comparada com aquelas que criam barreiras para ascensão das mulheres nos cargos de chefia, uma vez que não houve relação negativa entre desempenho e a maior participação feminina. A exemplo disso, a proporção de mulheres no conselho de administração influencia positivamente no retorno sobre o patrimônio líquido e a proporção de mulheres na diretoria influencia positivamente o valor de mercado das organizações.

Conforme literatura, a participação feminina nos conselhos e em cargos de chefia pode trazer vantagens ligadas ao desempenho econômico-financeiro, no que tange a adoção de melhores mecanismos de governança, remuneração dos executivos, elaboração de novas estratégias, qualidade dos resultados e melhor compreensão, por parte do mercado, dos investidores e demais usuários externos (ROBINSON; DECHANT, 1997; MYERS, 2003). Desse modo, supõe-se que a incidência de Glass Ceiling não é decorrente dos shareholders, mas dos agentes intraorganizacionais. $\mathrm{O}$ fato de haver pouca influência positiva entre a incidência de glass ceiling nos cargos de board e impacto no desempenho econômico e financeiro das organizações amplia a baixa pressão por parte dos stakeholders para a redução nas práticas discriminatórias de gênero nos cargos de conselhos de board. Portanto, a intervenção dos stakeholders parece ser uma alternativa para que haja redução na desigualdade de gênero nos cargos de topo.

Ramdhony, Oogarah-Hanuman e Somir (2013), comprovam que as barreiras que impedem o avanço das mulheres ao longo da carreira são, principalmente, o glass ceiling e os conflitos entre as demandas de suas vidas profissionais e pessoais. Portanto, pelos resultados sugere-se que as empresas priorizem a buscarem pela retenção, desenvolvimento, flexibilidade e progressão da carreira das mulheres no local de trabalho. Essas ações podem fazer com que as mulheres com dupla jornada, doméstica/familiar e profissional (demandas pessoais e profissionais), consigam almejar os cargos de topo das grandes corporações.

Os resultados corroboram com a afirmação de Gonçalves et al. (2016), em que a gestão da diversidade de gênero é uma ferramenta que gera valorização e promove o bem-estar da corporação, além de reter talentos e favorecer o sucesso organizacional. Conclui-se que os 
analistas de mercado, acionistas minoritários e majoritários, auditores e instituições de crédito podem se utilizar-se destes achados para começar a dar prioridade na análise das empresas que praticam o glass ceiling, visto que a promoção da igualdade de gênero pode ser útil na melhoria dos negócios corporativos, crescimento organizacional e valorização mercadológica.

Para futuras pesquisas, recomenda-se que sejam incluídas variáveis de estrutura da governança corporativa e demais atributos internos inerentes ao monitoramento das decisões organizações que impactam no alcance do desempenho organizacional. Esses fatores podem ter efeito moderador sobre a relação entre o glass ceiling nos cargos de board e as práticas organizacionais. A incidência do glass ceiling, também pode ser observada em função de outros cargos organizações, e seu impacto em decisões financeiras, contábeis e operacionais.

Como limitação pode-se salientar que não foi observada a qualificação acadêmica e profissional das mulheres que estão ocupando os cargos de board. Além disso, não foi observada a existência de vínculo familiar entre empresa e as mulheres que ocupam cargos de board, fator que pode impactar na observância do glass ceiling, visto que a promoção das mulheres pode não ter acontecido única e exclusivamente em função dos aspectos profissionais, mas oriundo do vínculo familiar com os fundadores e acionistas majoritários da empresa.

\section{Referências}

ADAMS, R. B.; FERREIRA, D. Women in the boardroom and their impact on governance and performance. Journal of Financial Economics, v. 94, n. 2, p. 291-309, 2009. DOI: 10.1016/j.jfineco.2008.10.007.

ALMEIDA, R. S. D.; KLOTZLE, M. C.; PINTO, A. C. F. Composição do Conselho de Administração no Setor de Energia Elétrica do Brasil. Revista de Administração da UnimepUnimep Business Journal, v. 11, n. 1, p. 156-180, 2013. DOI: 10.15600/16795350/rau.v11n1p156-180.

ANDRADE, L. P. D.; SALAZAR, G. T.; CALEGÁRIO, C. L. L.; SILVA, S. S. Corporate governance: an analysis of board of directors in relation with the value of market and performance of the Brazilian companies. RAM. Revista de Administração Mackenzie, v. 10, n. 4, p. 4-31, 2009. DOI: 10.1590/S1678-69712009000400002.

BEZERRA, F. A.; CORRAR, L. J. Utilização da análise fatorial na identificação dos principais indicadores para avaliação do desempenho financeiro: uma aplicação nas empresas de seguros. Revista Contabilidade \& Finanças, v. 17, n. 42, p. 50-62, 2006. DOI: 10.1590/S1519-70772006000300005.

BJERK, D. Glass ceilings or sticky floors? Statistical discrimination in a dynamic model of hiring and promotion. The Economic Journal, v. 118, n. 530, p. 961-982, 2008. DOI: 10.1111/j.1468-0297.2008.02157.x.

BLAU, F. D.; DEVARO, J. New evidence on gender differences in promotion rates: An empirical analysis of a sample of new hires. Industrial Relations: A Journal of Economy and Society, v. 46, n. 3, p. 511-550, 2007. DOI: 10.1111/j.1468-232X.2007.00479.x.

BRASIL, L.; PEREIRA, A. N.; MACHADO, V. L. A inserção do gênero feminino na empresa vis-à-vis a participação feminina na população economicamente ativa: um estudo de caso da 
companhia energética do Paraná (COPEL). Gestão e Sociedade, v. 3, n. 5, p. 95-113, 2009. DOI: $10.21171 /$ ges.v3i5.690.

BRUSCHINI, M. C. A. Trabalho e gênero no Brasil nos últimos dez anos. Cadernos de pesquisa, v. 37, n. 132, p. 537-572, 2007. DOI: 10.1590/S0100-15742007000300003.

CAMBOTA, J. N.; PONTES, P. A. Desigualdade de rendimentos por gênero intraocupações no Brasil, em 2004. Revista Economia Contemporânea, Rio de Janeiro, v. 11, n. 2, p. 331350, 2007. DOI: 10.1590/S1415-98482007000200006.

CARTER, D. A.; SIMKINS, B. J.; SIMPSON, W. G. Corporate governance, board diversity, and firm value. Financial Review, v. 38, n. 1, p. 33-53, 2003. DOI: 10.1111/1540-6288.00034.

CATELLI, A. (Coord.). Controladoria: uma abordagem da gestão econômica-GECON. São Paulo, Atlas, 1999.

DAILY, C. M.; CERTO, S. T.; DALTON, D. R. Research notes and communications a decade of corporate women: Some progress in the boardroom, none in the executive suite. Strategic Management Journal, v. 20, n. 1, p. 93-99, 1999. DOI: 10.1002/(SICI)1097-0266.

DEWATRIPONT, M.; JEWITT, I.; TIROLE, J. The economics of career concerns, part II: Application to missions and accountability of government agencies. The Review of Economic Studies, v. 66, n. 1, p. 199-217, 1999. DOI: 10.1111/1467-937X.00085.

DOBBIN, F.; JUNG, J. Corporate board gender diversity and stock performance: The competence gap or institutional investor bias? North Carolina Law Review, v. 89, 2011.

DOMÍNGUEZ, L. R.; SÁNCHEZ, I. M. G.; ÁLVAREZ, I. G. Explanatory factors of the relationship between gender diversity and corporate performance. European Journal of Law and Economics, v. 33, n. 3, p. 603-620, 2012. DOI: 10.1007/s10657-010-9144-4.

FACCIO, M.; MARCHICA, M. T.; MURA, R. CEO gender, corporate risk-taking, and the efficiency of capital allocation. Journal of Corporate Finance, v. 39, p. 193-209, 2016. DOI: 10.1016/j.jcorpfin.2016.02.008.

FINKELSTEIN, S.; HAMBRICK, D. C. Strategic leadership: top executives and their effects on organizations. Australian Journal of Management, v. 22, n. 2, p. 21-224, 1997.

FISKE, S.; TAYLOR S. (1991). Social Cognition (2nd ed). McGraw-Hill: New York, 1991.

FRAGA, J.; SILVA, V. Diversidade no conselho de administração e desempenho da empresa: uma investigação empírica. Brazilian Business Review, v. 9, p. 58-80, 2012.

FRANCOEUR, C.; LABELLE, R.; SINCLAIR-DESGAGNE, B. Gender diversity in corporate governance and top management. Journal of Business Ethics, v. 81, n. 1, p. 83-95, 2008. DOI: $10.1007 / \mathrm{s} 10551-007-9482-5$.

GITMAN, L. J. Princípios da administração financeira. 10. ed. São Paulo, Pearson Addison Wesley, 2004. 
GIUBERTI, A. C.; MENEZES-FILHO, N. Discriminação de rendimentos por gênero: uma comparação entre o Brasil e os Estados Unidos. Economia Aplicada, v. 9, n. 3, p. 369-384, 2005. DOI: 10.1590/S1413-80502005000300002.

GONÇALVES, E. B. D. P.; ESPEJO, M. M. D. S. B.; ALTOÉ, S. M. L.; VOESE, S. B. Gestão da diversidade: um estudo de gênero e raça em grandes empresas brasileiras. Enfoque: Reflexão Contábil, v. 35, n. 1, p. 95-112, 2016. DOI: 10.4025/enfoque.v35i1.30050.

GONDRIGE, E. O. D.; CLEMENTE, A.; ESPEJO, M. M. D. S. B. Estrutura do conselho de administração e valor das companhias brasileiras. BBR-Brazilian Business Review, v. 9, n. 3, p. 72-95, 2012.

GUTNER, T. Wanted: More diverse directors. Business Week, v. 30, n. 134, p. 2001.

HUANG, J.; KISGEN, D. J. Gender and corporate finance: Are male executives overconfident relative to female executives?. Journal of Financial Economics, v. 108, n. 3, p. 822-839, 2013. DOI: $10.1016 /$ j.jfineco.2012.12.005.

HULTIN, M.; SZULKIN, R. Wages and unequal access to organizational power: An empirical test of gender discrimination. Administrative Science Quarterly, v. 44, n. 3, p. 453-472, 1999. DOI: $10.2307 / 2666958$.

IBGC - Instituto Brasileiro de Governança Corporativa. Código das melhores práticas de governança corporativa. 4. ed. São Paulo: IBGC, 2009.

IBGC - Instituto Brasileiro de Governança Corporativa. Níveis de Governança Corporativa. 2011. Disponível em: < http://www.ibgc.org.br/Secao.aspx?CodSecao=20>. Acesso em: $30 \mathrm{de}$ abr. de 2015.

KASSAI, S. Utilização da Análise por Envoltória de Dados (DEA) na Análise de Demonstrações contábeis. 350 fls. Tese (Doutorado em Ciências Contábeis) FEA- USP Universidade de São Paulo, São Paulo, 2002.

LEE, P. M.; JAMES, E. H. She'-e-os: gender effects and investor reactions to the announcements of top executive appointments. Strategic Management Journal, v. 28, n. 3, p. 227-241, 2007. DOI: 10.1002/smj.575.

MADALOZZO, R. CEOs e composição do conselho de administração: a falta de identificação pode ser motivo para existência de teto de vidro para mulheres no Brasil? RAC - Revista de Administração Contemporânea, v. 15, n. 1, p. 126-137, Jan./Fev. 2011. DOI: 10.1590/S141565552011000100008 .

MADALOZZO, R. Teto de Vidro e Identificação: uma análise do perfil de CEO's no Brasil. Insper Working Paper, Insper Instituto de Ensino e Pesquisa, 2010.

MARGEM, H. R. Participação das mulheres no conselho de administração e diretoria, valor e desempenho das companhias brasileiras de capital aberto. 2013. Dissertação 
(Mestrado em Finanças e Economia Empresarial) - Escola de Pós-graduação em economia, Fundação Getúlio Vargas, Rio de Janeiro, 2013.

MARRY, C.; POCHIC, S. El "techo de vidrio" en Francia: el sector público es más igualitario que el privado?. Cadernos de Pesquisa [online], v. 47, n. 163, p.148-167, 2017. http://dx.doi.org/10.1590/198053144299. DOI: 10.1590/198053144299.

MARTINS, O. S.; MAZER, L. P.; LUSTOSA, P. R. B.; PAULO, E. Características e Competências dos Conselhos de Administração de Bancos Brasileiros e suas relações com seus Desempenhos Financeiros. Revista Universo Contábil, v. 8, n. 3, p. 40-61, 2012. DOI: 10.4270/ruc.2012321.

MATARAZZO, D. C. Análise financeira de balanços. 6. ed. São Paulo: Atlas, 2003.

MATARAZZO, D. C. Análise financeira de balanços: abordagem básica e gerencial. 3. ed. São Paulo: Atlas, 1995.

MATARAZZO, D. C. Análise financeira de balanços: abordagem básica e gerencial. 5. ed. São Paulo: Atlas, 1998.

MORRISON, A. M.; VON GLINOW, M. A. Women and Minorities in Management. American Psychological Association, 1990. DOI: 10.1037/0003-066X.45.2.200.

MYERS, A. O valor da diversidade racial nas empresas. Estudos afro-asiáticos, v. 25, n. 3, p. 483-515, 2003. DOI: 10.1590/S0101-546X2003000300005.

NEELY, A.; RICHARDS, H.; MILLES, J.; PLATTS, K.; BOURNE, M. Designing performance measures: a structured approach. International Journal of Operations \& Production Management, v. 17, n. 11, p. 1131-1152, 1997. DOI: 10.1108/01443579710177888.

NIELSEN, S.; HUSE, M. The contribution of women on boards of directors: Going beyond the surface. Corporate Governance: An International Review, v. 18, n. 2, p. 136-148, 2010. DOI: $10.1111 /$ j.1467-8683.2010.00784.x.

OHLOTT, P. J.; RUDERMAN, M. N.; MCCAULEY, C. D. Gender differences in managers' developmental job experiences. Academy of Management Journal, v. 37, n. 1, p. 46-67, 1994. DOI: $10.2307 / 256769$.

PARENTE, R. M. As Contribuições do Parecer CNE/CP 3/2004 para a Educação das relações Étnico-Raciais. In: AGUIAR, M. A. da S. et al (Orgs.). Educação e diversidade: estudos e pesquisas. Recife: Gráfica J. Luiz Vasconcelos, 2. 249-270, 2009.

PERRYMAN, A. A.; FERNANDO, G. D.; TRIPATHY, A. Do gender differences persist? An examination of gender diversity on firm performance, risk, and executive compensation. Journal of Business Research, v. 69, n. 2, p. 579-586, 2016. DOI: 10.1016/j.jbusres.2015.05.013. DOI: 10.1016/j.jbusres.2015.05.013. 
POWELL, G. N.; BUTTERFIELD, D. A. Investigating the "glass ceiling" phenomenon: An empirical study of actual promotions to top management. Academy of Management Journal, v. 37 , n. 1, p. $68-86,1994$. DOI: $10.2307 / 256770$.

RAMDHONY, D.; OOGARAH-HANUMAN, V.; SOMIR, N. Career progression of women in accounting - The case of Mauritius. International Journal of Humanities and Applied Sciences, v. 2, n. 1, 2013.

ROBINSON, G.; DECHANT, K. Building a business case for diversity. The Academy of Management Executive, v. 11, n. 3, p. 21-31, 1997. DOI: 10.5465/AME.1997.9709231661.

SANTOS, B. D.; SANTOS, D. C. D.; TORQUATO, M.; SEARA, L. D. S.; SCARPIN, J. E. Relação da estrutura de capital e a diversidade de gênero no conselho de administração. In: Semead, 20., FEA USP, 2017. Anais..., 2017.

SANTOS, G. C. M., RODRIGUES, I.; DUTRA, S. E.; COSTA, B. V. L. Gestão da diversidade: um estudo entre as melhores empresas para você trabalhar. In: XI Semead, FEA USP, 2008. Anais... Semead - Seminários em Administração, São Paulo, 2008.

SHRADER, C. B.; BLACKBURN, V. B.; ILES, P. Women in management and firm financial performance: An exploratory study. Journal of Managerial Issues, p. 355-372, 1997.

SILVA, J. P. Análise financeira das empresas. 9. ed. São Paulo: Atlas, 2008.

SILVA, W. M.; MAGALHÃES FILHO, P. A. O. Existe alguma associação entre governança corporativa e diversificação na firma? Um estudo empírico com indústrias brasileiras. In: ENAMPAD, 28, Curitiba/PR. Anais... Rio de Janeiro: ANPAD, 2004.

SMITH, N.; SMITH, V.; VERNER, M. Do women in top management affect firm performance? A panel study of 2,500 Danish firms. International Journal of Productivity and Performance Management, v. 55, n. 7, p. 569-593, 2006. DOI: $10.1108 / 17410400610702160$.

SOUZA, F. M. D.; VOESE, S. B.; ABBAS, K. Mulheres no topo: as contadoras paranaenses estão rompendo o Glass Ceiling? Advances in Scientific and Applied Accounting, v. 8, n. 2, p. 244-270, Mai./Ago., 2015. DOI: 10.14392/ASAA.2015080206.

TEIXEIRA, K. C. S.; GÓIS, J. B. H. Diversidade e equidade de gênero em empresas. Revista Gênero, v. 15, n. 2. Niterói, p. 155-162, 2015. DOI: 10.22409/rg.v15i2.659.

UN WOMEN - United Nations Entily for Gender Equality and the Empowerment of Women. Progresso of the World's Women 2015-1016: Transforming economies, realizing rights, 2015. Disponível em: $<$ http://progress.unwomen.org/en/2015/>. Acesso em: 25 de abr. de 2015.

VOLPIN, P. F. Governance with poor investor protection: Evidence from top executive turnover in Italy. Journal of Financial Economics, v. 64, n. 1, p. 61-90, 2002. DOI: 10.1016/S0304-405X(02)00071-5. 
WEARING, C. A.; WEARING, B. Between glass ceilings: Female non-executive directors in UK quoted companies. International Journal of Disclosure and Governance, v. 1, n. 4, p. 355-371, 2004. DOI: 10.1057/palgrave.jdg.2040036.

WESTPHAL, J. D.; MILTON, L. P. How experience and network ties affect the influence of demographic minorities on corporate boards. Administrative Science Quarterly, v. 45, n. 2, p. 366-398, 2000. DOI: 10.2307/2667075.

WOLFERS, J. Diagnosing discrimination: Stock returns and CEO gender. Journal of the European Economic Association, v. 4, n. 2-3, p. 531-541, 2006. DOI: 10.1162/jeea.2006.4.23.531 . 